\title{
The Rapid Developed Ovarian Krukenberg Tumors after Ovarian Hyperstimulation: a Case Report and Discussion
}

Shu Zhu ${ }^{1}$, Xia Wang ${ }^{2}$, Cong Wang ${ }^{1}$, Meng Zhao ${ }^{1}$, Huihua Dai ${ }^{1}$, and Xiuli wang ${ }^{3}$

${ }^{1}$ Jiangsu Province Hospital and Nanjing Medical University First Affiliated Hospital

${ }^{2}$ Nanjing Medical University

${ }^{3}$ Affiliation not available

June 9,2020

\section{Hosted file}

manuscript.doc available at https://authorea.com/users/331345/articles/458046-the-rapiddeveloped-ovarian-krukenberg-tumors-after-ovarian-hyperstimulation-a-case-report-anddiscussion

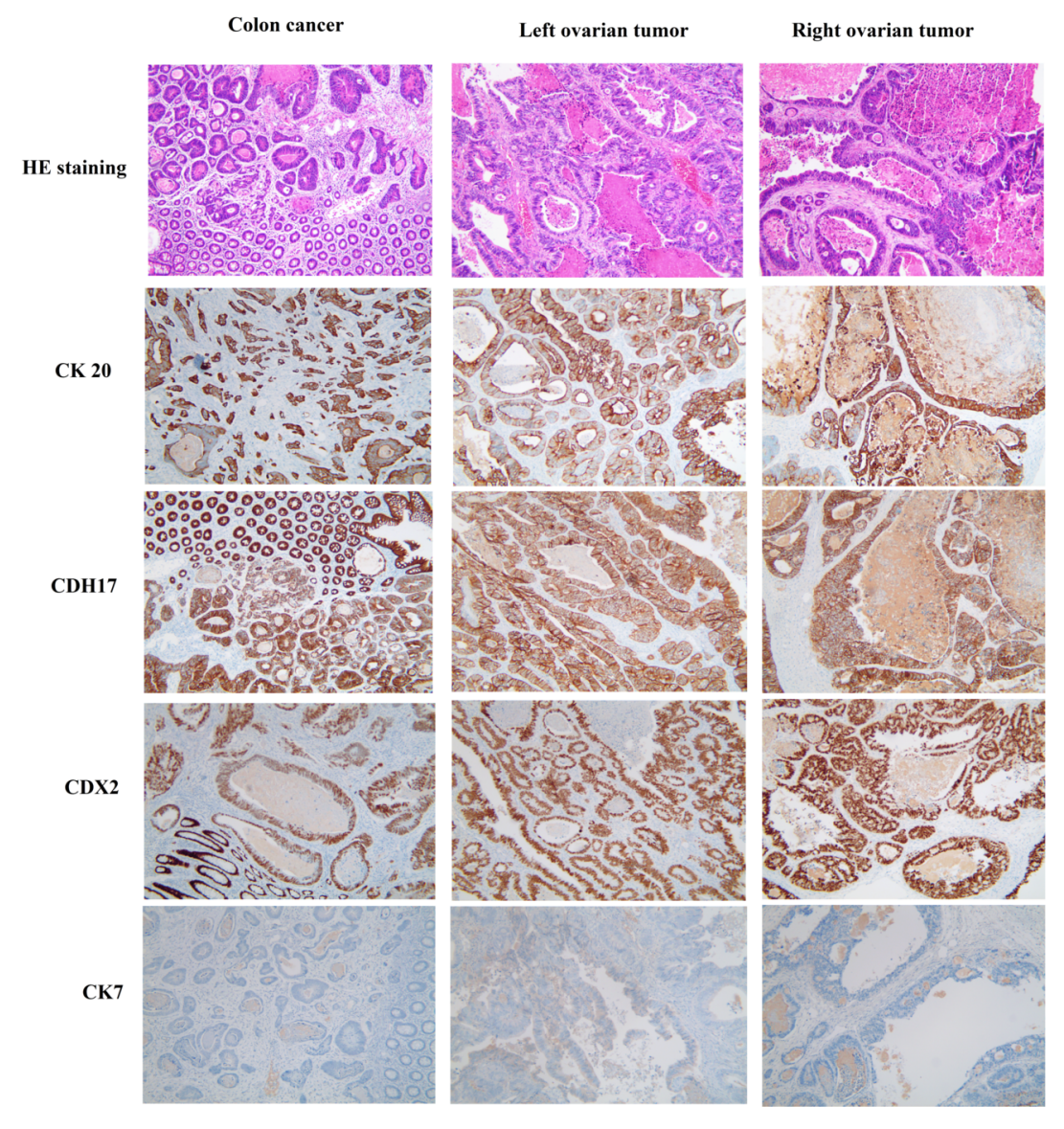

